\title{
Need and Motivation in Learning English Language
}

\author{
Ervin Balla \\ PhD Candidate, University of Tirana, Albania \\ Email: Ervin_balla@yahoo.com
}

\section{Doi:10.5901/mjss.2014.v5n6p217}

\begin{abstract}
In our times all are headed to the important process of acquiring the English Language due to the important role that this language is gaining. There are some criterias to acquire this language such as the need and motivation, that if are taken seriously very high results can be achieved. We try to do everything that it takes to teach English to our students, and several factors should always be taken into consideration to make it possible. Some of these factors are taken into consideration in my work.
\end{abstract}

Keywords: English language, motivation, need, learning, teacher.

\section{Introduction}

\subsection{The need and motivation}

Motivation is a kind of inner urge incouraging someone to follow an activity. If we have a purpose to achieve something and if this purpose is very attractive to us, we can be highly motivated to do what it takes to accomplish it. Aims can be of various types, for example if we have decided to have a new CD player, a bicycle or a new car we can work for long hours to make the money to buy what we want. Even the motivation in learning the foreign language works in the same way. A man who is motivated to learn a foreign language feels the same inner attraction urged by the need that he has to learn this language.

During the classes the teachers give to the students various assignments. What do we mean with "assignments"?

- An activity that involves the individuals in the usage of the language aiming to achieve a target or a goal in a given situation (Bachman and Palmer 1996).

- A class work involves the students in the understanding, manipulation, and production of the language (Avermaet and Gysen 1996). To meet these assignments successfully students need motivation. Motivation makes the students more effective during their working time. The ability to learn and think is closely connected with the processes of comunication (Powell and Powell 2010)

Students are motivated if their teacher is communicative. Some students have a low self esteem and a negative attitude for the way of learning. In this case is the possibility to strengthen these negative feelings, making the student to believe that he is incapable to learn the foreign language. Sometimes they limit their knowledge and understanding to their former experiences which might not have been very successful (Loughran and Russell 2003).

If the student does not believe that he has the abilities to perform a task he may fail it. In these cases the motivation from the teacher is decisive.

When the student believes that he is going to succeed it, than he with the personal belief resist the failure (Tamo and Rapti 2005). This means that he has to determine his aims and goals. It is important for the student to take over the responsibility of learning, to accept the risk and face it successfully (Aliu 2004). Very frequently the teachers ask the students and instead of motivating them, they do the contrary (Linch 1996). Most of the time in the class the teachers talk without giving the possibility to the students to express themselves, except in the cases when he asks them questions. Even in those cases he punishes them for their mistakes (Manmatha Kundu 1993). Even when the teacher decides to incourage the students, it can be very difficult for them to stay away from the traditional role of the teachers (Tony Lynch 1996).

One of the most important experiences of the learning has taken place by the end of the second warld war, when the American army needed to train their staff in the languages of the countries that they had to administrate, or deal with small intensive courses the students learned the languages extremely fast (Harmer 2001) Whatever was the method 
used to learn the languages they were higly motivated to learn the languages. They really wanted to learn and they had really very strong reasons to do that, including also the fear of failure.

The will to learn comes from many sources, maybe students like the subject, or simply they want to see what is about. On the other side thay can have a practical reason for doing it. For example people learn to play an instrument because they like musicand maybe they want to paly in a musical band, or learn English because thay want to see American movies, or British TV channels, or they simply want to listen to music and understand the lyrics of the songs.

\section{Other Factors that Attract the Learner of a Language}

Famous researches made in the second half of the twenty century made by (Gardener and Lambert 2005) suggested that the students were attracted more by a language that they wanted to integrate in its culture or the culture of the people that spoke that language, than they who learnt the language as an instrumental motivation. For this kind of motivation the students were attracted by the culture of the community that speaks that language and usually those students have a strong desire to integrate in that language. There are many reasons for that. It is worth to mention here the fact that learning the language focusing in the culture of the people who speak that language has to do with deep studies and not superficial ones, as in the case of study of the professional vocabolary of that language.

Profound studies of the culture of that language have to do with many other important factors of the language such as culture, history, tales, epos, legends myths of this country etc. Focusing into this kind of study and the approach with this language will lead into an attraction for this language (and not only to the mastering to that limited part of vocabolary that has to do with this process) it will take to a greater recognition of the vocabolary and the culture of this country. This kind of approach will lead into attraction to the tradition of this country, so not only seeing from the outside the language but also focusing into the most important part of the language the integrative motivation, that is a motivation that plays an important role in the mastering of the language. Of course this kind of motivation is used frequently by the students of the English language or those who want to do profound studies in English language. Also the instrumental approach plays an important role in the learning of the English language, especially in what is called professional language, so it has to do with profound studies in a given profession.

Many other factors have an influence on the level of motivation of the students and most of them have to do with their attitude toward the language (Peter Westwood 1995). Another factor that influences the attitude of the students toward the language is his previous experience in the learning the language. If they have been successful before, they will be successful now. The contrary could happen if they wouldn't have been successful before. In this regard we raise the question: what can the teachers do for the extrinct motivation of the students and for their attitude toward the language?

It is clear that we can not create the extrinct motivation since it comes from the outside of the class. It is clear also that the students are prepared to take responsibility for their learning. Taking this into consideration, we can do the best to make sure that the students see the language and the experience of the language learning with a positive aspect. We can do this by creating positive attitudes to those who want to learn it

The physical conditions have a great influence in learning and can influence the motivation of a student positively or negatively. Tha badly lighted classrooms and overcrowded are demotivating and unfortunately thew exist in our schools.

\section{Learning as a Complex Process}

Learning is a complex process made up by various factors intertwined with each other (Heargraves 1993). Teachers will be more effective in the classrooms if we have a deeper understanding of these factors, when they develop learning strategies that meet their instructive goals and address these things to their students. To achieve these things, we should take these three factors into consideration;

1. Abilities of the students

2. Comunication with them

3. Their motivation to achieve their goal

The pleasure grows more the effectivity to study English language. If we like to study English and spend more time doing it we will do it regularly. A high level of motivation will give another advantage.

It will be much easy for us to memorise new words and gramatical structures. The reason for this is that brain remembers easily information for a subject that we like rather than for a subject that we don't like.

The pleasure of learning gives us the double of benefit if we like it. This is a very profitable way to increase the 
interest of the students to learn foreign languages. If the topics and the debates during the classes will be very interesting, it will attract the interest of the students to learn the foreign languages, and to memorise better the words and gramatical structures of the languages (Westwood 1995).

If the lectures are illustrated with many events explained in English languages then the students will be able to relate the new words with the situations and in this way the memorising the nwe words will be easier. All the students of the English language would like to speak English fluently, and they are all excited to the idea of being able to speak a foreign language. Anyway very frequently they do not show the right interest for the process of learning. For most of them learning is just an assignment. They do not feel the pleasure of learning English if the learning is turned into obligation.

The adults live in a world where the English language is very important for them (Broughton 1993). So all the students of English would like to speak English fluently, but they would not like to get involved in the process of learning. Theoretically this the biggest problem that a student and a teacher of English face during the proces of learning, so if the students of English does not like to study English, so the process of learning will turn into a boredom and very frequently they will start to lose interest in it.

But regardless the motivation of the student to learn the language is always better than the student that does not have a motivation at all. According to my ten years experience in the field of teaching the students that does not have any kind of motivation to learn the English language (or any other foreign language) will soon loose the interest in the learning of that language? The motivation can be long term and short term.

With a long term motivation I would mention that motivation that has to do with the will to use the language as a mean of communication with the foreigners, study of the materials such as books in English, and the short term motivation can be obtaining a good grade by the end of the term for example.

In the cases when the long term motivation does not exist but only the short term one, such as the good grade by the end of the term, and by encountering several difficulties that an adult may have especially when he has never had any previous contact with the English language that this kind of motivation begins to faint. The student is not willing to continue to cooperate and expresses almost always the opinion that learning a foreign language is something very difficult, and everything is related to the age (so, this is not an apropriate age to learn a foreign language, according to him). He becomes unatentive during the classes, wants to speak only in Albanian or in some cases simply justifies with the fact that "when he was young in Albania was spoken only Russian"

So this kind of motivation is not long term and can not motivate the student for a long time to be focused in the learning the foreign language. In some cases aspecially when the classes are made up by several levels of students in English language, it may happen very frequently that the students are fluent in English, they may loose the interest very quickly for the things explained during the classes, because as they say "we know these things" and becoming an obstacle for the normal routine of the class.

\section{Long Term Motivation}

Regarding the long term motivation that has to do with the learning of the English of the students who use English language for translation, or contact with other people from all the world (globalisation of the English language) is more profitable. Due to globalisation of the English language, its great extension, adults are more sensible for the importance of this language is getting in our days.

From this we come into conclusion that all of them with a positive behaviour toward their subject (in this case learning the foreign language) are apt to learn it or to have a great expectation in improving they skills in language, but what should we do with them who do not have this kind of behaviour? Will they fail in the process of learning the language?

One of the main duties of the language students is urging the interest and the involvment in the subject even though the students are not interested primarly in it. It is of their choice the activity, or language content that can make the class be interested in the learning of the foreign language. It is in their hand, their persistance to influence their students. However the teachers are not the main responsibles for the motivation of their students (Jeremy Harmer 2010). As we mentioned earlier, the true motivation for the learning of the foreign language comes from inside of every student.

The students who find themselves into situation where the language is necessary for communication can be tought very differently from the students who learn the language without any kind of interest.

The majority of the students that make the choice to study a foreign language do it for a mixture of reasons mentioned above. This may lead to a question. Why are some students successful in the learning a foreign language and some others are not. Of course answering this question it is not easy and several factors can be mentioned, that may have a great influence to the success or failure in this process. 
The people involved in teaching very frequentl say that the students who really want to learn the language will succed regardless the circumstances tha they study. All the teachers could think about situations in which the motivated students succeed better than their peers.

Very frequently the students succeed in very inapropriate conditions and thay also use inappropriate methods. In the presence of this phenomenon it is reasonable to that the motivation that the motivation that the student may have is the biggest factor that influences this process.

\section{Type of Motivation}

What type of motivation may have the students? Is it always the same? We will divide them into two main categories.

1) External motivation

2) Interior motivation

The first has to do with the factors outside the class, while the second has to do with the factors inside the class. Both motivations are a fundamental part and play an important role in the learning of the foreign languages. Also the external motivation is divided into integrative motivation and instrumental motivation. As we stressed some students study a language because they have a better idea for something that they would like to achieve. The conclusion of Gardner and Lambert was that both forms of motivation are present to all the students but each of which expresses a variable influence depending on the age, experience, profession and social needs. So it is evdient that the motivation is complex case and highly individual.

That is why it can never be a very simple answer to this: "What motivates my students?" the need to answer to this question has led into a complex and involving answer: The adjustment to the need of everyone.

In practice this is interpreted as medical texts for the students of medicine, English texts for engineering for the engineering students and so on. However the students are not very enthusiastic if their texts innclude only texts of their future profession, and very frequently ask, why is happening this? What has to be taken into consideration in these cases is the fact that the students are people and not machines. So in the texts of medicine, engineering, law or economy should be sweetened with the idea of creativity feeling of achievements and every day situations in English language. So in other words the student will achieve pleasure by the actual experience of learning and not by the prospective of using what he has learned before.

\section{Conclusions}

As a conclusion we can say that learning is really a complex activitiy. We are attracted into the process of learning a language by many different factors. Some of them are external factors some of them are internal ones. No matter which is the urge what we as teachers of language (in this case of Enghlish language), but this can be the case for any language, we are really interested in doing it well, so we have to use any kind of urge for our students to make the language an object of their interest, and to achieve good results in our work.

\section{References}

Hutchinson T., (1987) "English for specific purpose" Kembridge University Press.

Corder N., (2008) "Learning to teach adults" Routledge

Harmer J., (2010) "How to teach English" Pearson Longman

Hutchinson T., \& Waters A, (1987), "English for specific purposes", Cambridge University Press

Louhgran J., \& Russell, T (1997)., "Teaching about teaching ", 2003 Falmer press

Tamo A, Rapti E, Karaj Th, (2005), "Mësimdhënia dhe të nxënit", Tiranë, Mokra,

Aliu I., (2004) "Metodologji e mësimnxënies", Tirane Pegi

Lynch T., (1996)" Communication in the language classroom", Oxford

Thomas S. Farrell C and George M. Jacobs (2010) "Essentials for Successful English Language Teaching" Continuum

Diller, K. C., (1971). "Generative Grammar, Structural Linguistics, and Language Teaching.: Newbury House Publishers

Coleman, A., (2012) "The Teaching of Modern Foreign Languages in the United States". Literary Licensing, LLC

Howatt, A. P. R., (198 4) "A History of English Language Teaching". Oxford University Press

Gauntlett J. O., (1957) "Teaching English as a Foreign Language". London: Macmillan

Palmer, H. E., (1968), "The Scientific Study and Teaching of Languages". London: Oxford University Press,

Thorne. K., (2003) "Blended Learning: How to Integrate Online and Traditional Learning" Great Britain Clays

Macdonald J., (2008) "Blended learning and online tutoring" England, Gower publishing

Palmer, H. E. (1934) "Specimens of English Construction Patterns". Department of Education 
Billows, F. L. , (1961). "The Techniques of Language Teaching. London": Longman

Jakobovits, L. A., ( 1970). "Foreign Language Learning: A Psycho linguistic Analysis of the Issues". Newbury House Bentley T., (1998) "Learning beyond the classroom "Routledge

Richard J and Rodgers Th., (2001) "Approaches and methods in language teaching" Cambridge University Press

Burton G., (1980) "Teaching English as a foreign language" New York Routledge 
